\title{
The influence of Rolling process on the porosity and wear behavior of Spray-formed Al-6\%Si-20\% Pb
}

\author{
Devendra Singh, Kavita puri, vinod kumar \\ Department of Metllurgical \& Materials Engineering, Indian institute of technology Roorkee, Roorkee, india
}

\begin{abstract}
Spray forming, also called spray casting or spray deposition, is the inert gas atomization of a liquid metal stream into variously sized droplets. These droplets are interrupted by a substrate which collects and solidifies the droplets into coherent, near fully dense perform. The present work concerns with this techniques. This technology was applied to produce Al-6\%Si-20\% Pb alloys. The spray droplets were deposited over a copper substrate to achieve a disc shape perform. After spray deposition samples were rolled at room temperature on two high rolling mills and total porosity and wear characteristic of spray deposits were studies. The total porosity decreases with the increase in the percentage of reduction in thickness of the samples. Thickness of the samples in both middle and peripheral region. Wear testing of spray formed and rolled Al-Si$\mathrm{Pb}$ alloy were investigated on a pin on disc type wear machine. Wear rate behavior with applied load and increase in percentage of reduction in thickness of samples was observed. Wear rate increased with increasing the load and decreased with increase in percentage of reduction in thickness of the sample.
\end{abstract}

Keyword: Al-Si-Pb alloy, Rolling, Spray forming, Total porosity, Wear characteristic

\section{Introduction}

In recent years, thermal spray deposition processes have created an exciting new opportunity in the synthesis of advanced materials. This process involves atomization of a molten materials by High velocity gas jets into a spray of micron-sized droplets, which are deposited onto a substrate. Rapid solidification inherent in spray atomization, due to high heat exchange rate at the droplet-gas interface and also on deposition surface, provides considerable chemical and microstructural homogeneity as well as refinement in the grain size of the deposit [1]. It has been shown that a too large deposition distance generates a law volume fraction of the liquid on the deposition surface. This effect leads to poor bonding of particles and increased porosity of the deposit. Alternatively, a small deposition distance gives rise to increased liquid fraction that leads to gas entrapment and slow cooling rate of the spray deposit [1,2]. The liquid immiscible alloys of Al-Pb-Si system are potential materials for bearing alloys. Bearing material should have the following characteristics; embeddability, compatibility, conformability, fatigue resistance and corrosion resistance for a longer service life, high strength to weight ratio[3]. Immiscible alloys such as $\mathrm{Al}-\mathrm{Pb}, \mathrm{Al}-\mathrm{Bi}$ alloys can not be cast using conventional casting methods due to large density difference between the two phases in their liquid state [ 4,5]. A slow cooling rate associated with conventional casting process resulted in rapid separation of $\mathrm{Al}$ and $\mathrm{Pb}$ rich phases[6]. Several methods different from the conventional casting have been employed to produce immiscible Al-Pb alloys such as stir casting[5,7 ], rehocasting [8], rapid solidification[6],powder metallurgy[3],melt spinning[9],strip casting[10] and spray forming[6,11]. However some of these techniques face problems of higher energy consumption or generation of coarse. Among these techniques spray forming possesses several advantages in effective micro-structural control together with producing a near net shape perform in a lesser number of processing steps[12]. Rapid cooling associated with solidification of atomized droplets and a turbulent fluid flow condition on the deposition surface minimize the separation of the $\mathrm{Al}$ and $\mathrm{Pb}$ rich phases[6,11]. However a high melt temperature result in rapid coarsening of $\mathrm{Pb}$ particles in this process. In the present work $\mathrm{Al}-\mathrm{Si}-\mathrm{Pb}$ alloys were spray formed in the form of disc and their characteristics such as shape, microstructure, porosity, hardness, wear etc. were studied. The central and peripheral region of spray formed $\mathrm{Al}-6 \mathrm{Si}-20 \mathrm{~Pb}$ were rolled to a thickness deformation of $20,40,60$,and $80 \%$. After rolling porosity, and wear rate were studied.

\section{Experimental Procedure}

A schematic of spray forming set-up is shown in figure 1. The alloy was allowed to melt into a graphite crucible placed inside a furnace as shown in the figure1. At centre of the bottom of 


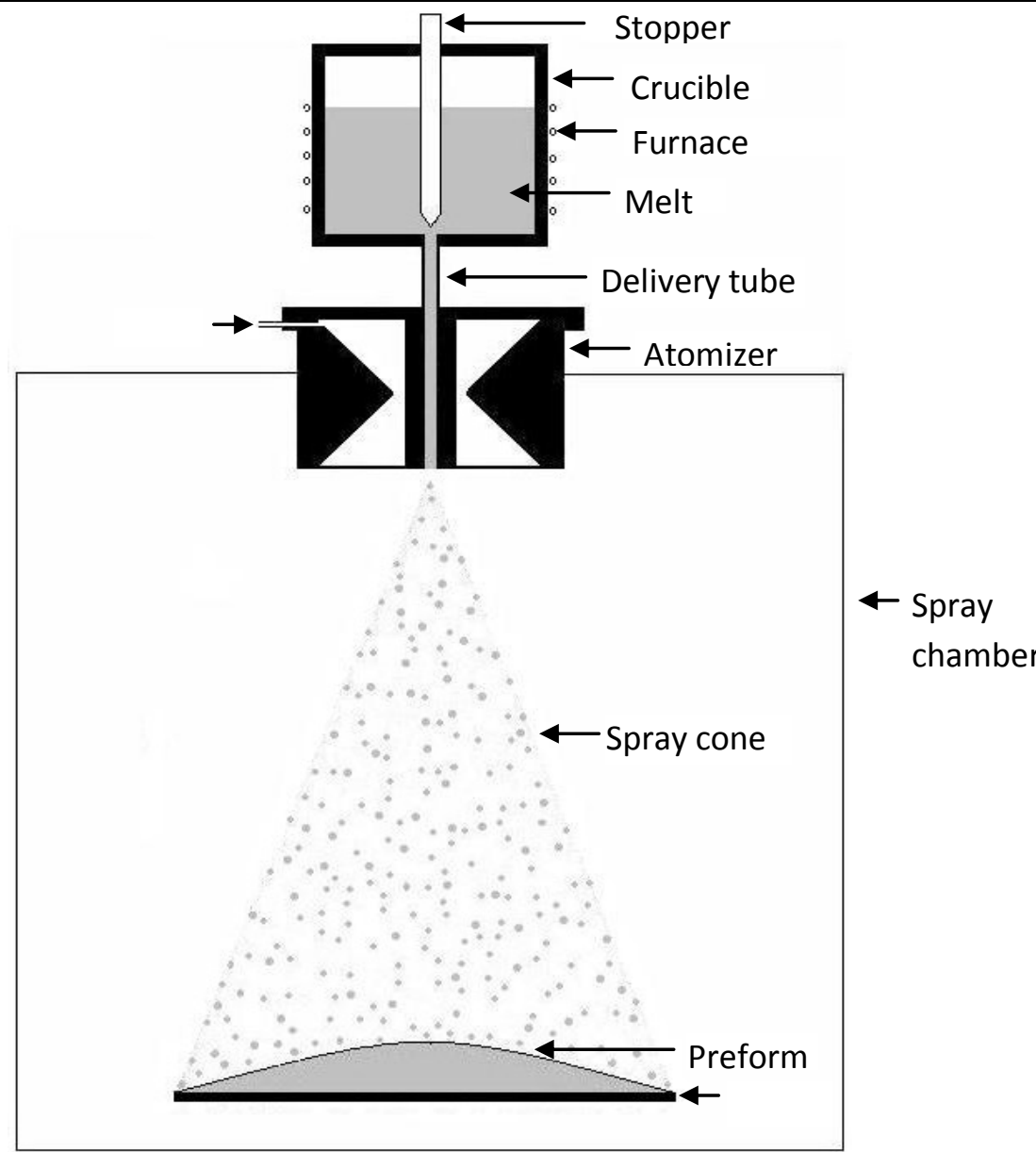

Fig1.Schematic of spray forming process.

crucible an exchangeable graphite melt delivery tube was fitted to produce melt floe stream. A stopper rod was used to either open or close the entrance of the delivery tube. Other end of delivery tube was fitted into the atomizer which was placed above the cooling chamber. Height of cooling chamber was $1500 \mathrm{~mm}$. the stopper rod was raised up after starting the gas flow in atomizer to start the atomization of melt and there by spray deposition. Vertically falling liquid metal stream interacts with high energy jet at the tip of melt delivery tube which promotes the atomization of melt into spray of all small size droplets. This atomization take place inside the cooling of spray chamber and atomized droplets were deposited over a copper substrate which can be placed at a different distances from the atomizer. The base alloy used in the present work consisted of $\mathrm{Al}-\mathrm{Si}$ alloy having $12 \%$ and $24 \% \mathrm{Si}$. The alloy was superheated to $200 \mathrm{C}$ above its melting point. In each run $800 \mathrm{gm}$ of $\mathrm{Al}-\mathrm{Si}-\mathrm{Pb}$ alloy was taken in the crucible. Nitrogen gas was supplied for atomization prior to melt flow. The atomization was carried out at a nitrogen gas pressure of 10 bar. The details of the process variables are given in table 1. The preform was taken out of the substrate after deposition.

Table 1: Values of various variables used in present study

\begin{tabular}{lc} 
Conducted study & Spray deposition \\
Alloy composition (wt\%) & Al-6Si-20Pb \\
\hline Melt temp & 820 \\
\hline Distance from atomizer to substrate & $450(\mathrm{in} \mathrm{mm})$ \\
\hline $\begin{array}{l}\text { Weight of alloy taken for each } \\
\text { run }\end{array}$ & $800 \mathrm{gm}$ \\
\hline Melt delivery tube diameter & $5 \mathrm{~mm}$ \\
\hline Substrate thickness & $8 \mathrm{~mm}$ \\
\hline
\end{tabular}

The cold rolling was performed on a two-high mill with rolls of $100 \mathrm{~mm}$ in diameter. The middle and peripheral region strips were rolled to a thickness deformation of $20,40,60$ and $80 \%$. Samples were rolled at room temperature. After rolling porosity and wear rate were measured. Samples were cut from centre of spray deposit and prepared by using standard metallographic techniques. To measure total porosity at different locations of the deposit, samples were cut from different location as shown in 
figure 2. The total porosity was calculated by Archimedes principle and followed the ASTM B 328-96 practice. . The total porosity was calculated from the following equation.

$$
\text { Total Porosity }=1-\frac{\text { Measured density of sample }}{\text { Theoretical density of sample }}
$$

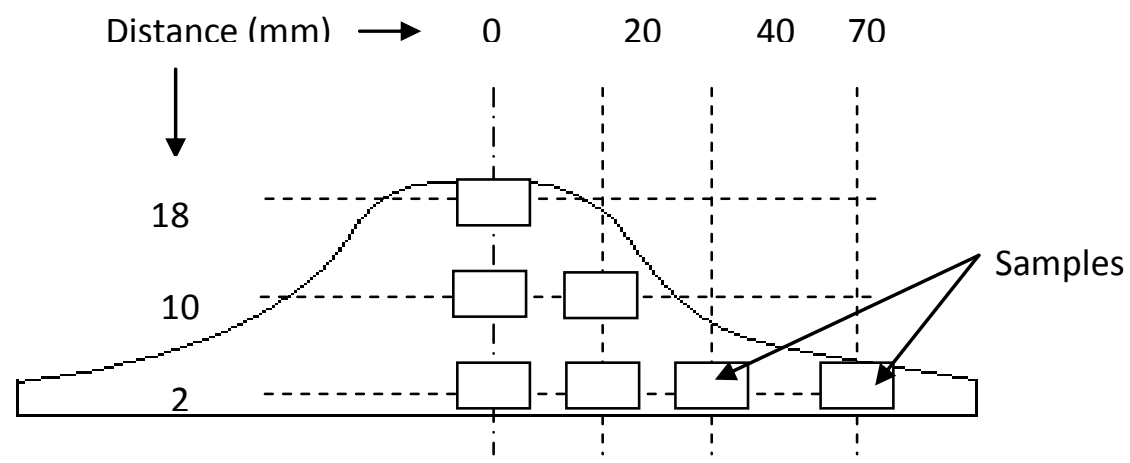

Figure2. Locations of samples cut from spray deposit for porosity measurement

The spray formed preform with different thickness reduction were machined into cylindrical pins of dimensions $5 \mathrm{~mm}$ diameter x $15 \mathrm{~mm}$ length. Specimens were thoroughly degreased by acetone and dried before the commencement of each wear test. Wear testing of spray formed and rolled alloys were investigated using a pin on disc type wear testing machine. It consisted of a hardened EN-24 steel disc (surface roughness $=0.4-0.5 \mu \mathrm{m}$ ) of diameter $12 \mathrm{~cm}$ with Rockwell hardness of $57 \mathrm{HRC}$ and a specimen holder. Steel disc was grounded to smooth surface finish and thoroughly degreased with acetone. Wear test specimen was mounted in the specimen holder. The load on the specimen was applied by placing a load on the opposite side of a fulcrum of the lever attached to the specimen holder. Rotation speed of the disc was kept constant at $171 \mathrm{rpm}$ at the position of the pin throughout the investigation. The radius of rotation was fixed at $56 \mathrm{~mm}$. The samples were run for a period of 10 minutes before determining their weight loss which was used to find the resultant wear rate. Sliding distance for one run was $600 \mathrm{~m}$ and sliding speed was $1 \mathrm{~m} / \mathrm{s}$. The standard wear test procedure was followed for evaluating the wear rate for different load ranging from 5 to $15 \mathrm{~N}$. The disc surface was cleaned with acetone before each experiment. All the tests were carried out in dry sliding conditions and at room temperature. Pin specimens were weighed both before and after testing on a single pan electrical balance that gave reading to $0.01 \mathrm{mg}$.

\section{Results And Discussions}

3.1 Theoretical density calculated for the alloys used in present study is given below and measured densities are reported with their location in the spray deposit in fig.3

\begin{tabular}{|lr|}
\hline $\begin{array}{l}\text { Density }(\mathrm{g} / \mathrm{cc}) \\
\text { alloy }\end{array}$ & 3.15 \\
\end{tabular}

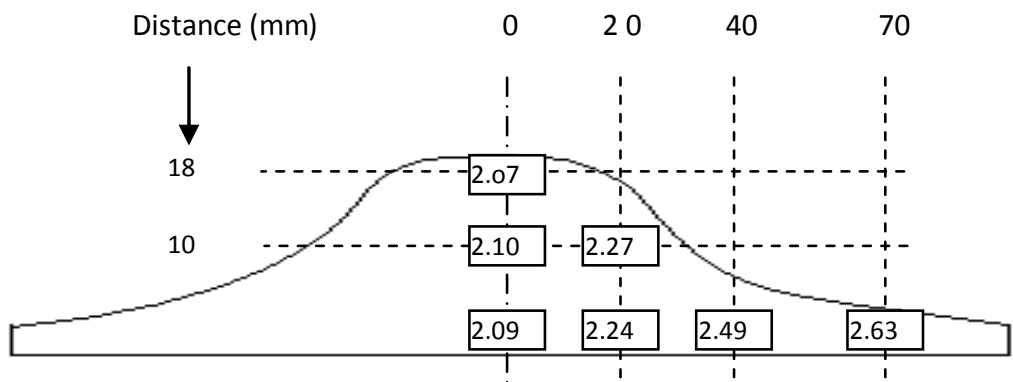

Fig3.Measured densities in 'the spray deposit. 


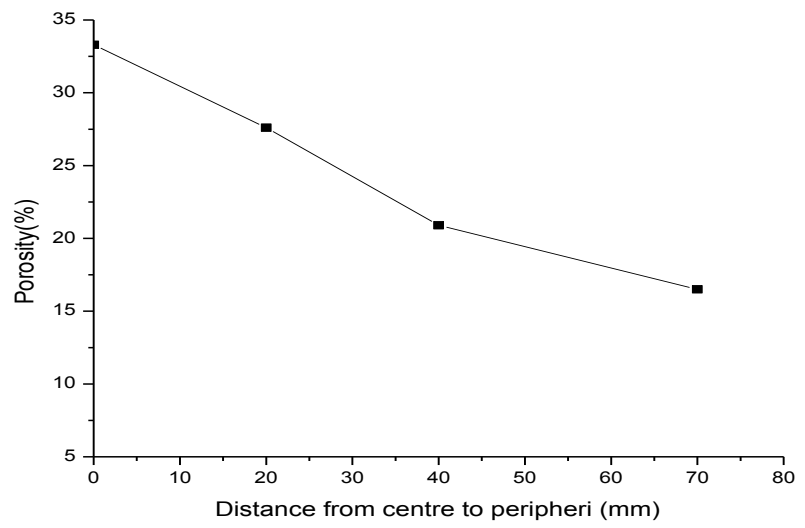

Fig 4. Variation in porosity with distance from centre to periphery of spray deposited preform.

The total porosity calculated from these densities is shown in figure 4 as a function of distance from center to periphery. It can be seen from fig that their is no change in density and also in porosity in the thickness direction. The change in density and hence porosity is observed with the increase in distance from the centre to periphery of the deposit. It can be seen from fig that porosity decreases with the increase in distance from center to periphery.

\subsection{POROSITY IN SPRAY DEPOSIT (AFTER ROLLING)}

Samples were cut from the middle and peripheral region of the perform and reduce thickness $20 \%$, $40 \%, 60 \%$ and $80 \%$ in both regions by rolling operation and prepared by using standard metallographic techniques. The density and porosity for the various percentage of reductions in middle and peripheral were measured by using the Archimedes's Principle. The result are shown in the following table

Table 2..Measured density and porosity in middle region for different percentage of reduction in thickness of the samples.

\begin{tabular}{lll}
$\begin{array}{l}\% \text { of reduction } \\
\text { in thickness }\end{array}$ & $\begin{array}{c}\text { Measured } \\
\text { density }\end{array}$ & $\%$ of porosity \\
\hline 20 & 2.26 & 28.2 \\
\hline 40 & 2.37 & 24.5 \\
\hline 60 & 2.51 & 19.9 \\
\hline 80 & 2.67 & 15.2 \\
\hline
\end{tabular}

Table 3.Measured density and porosity in peripheral region for different percentage of reduction in thickness of the samples.

\begin{tabular}{lcc}
$\begin{array}{c}\% \\
\text { of } \\
\text { thickness }\end{array}$ & reduction & in $\begin{array}{c}\text { Measured } \\
\text { density }\end{array}$ \\
\hline 20 & 2.69 & 14.7 \\
\hline 40 & 2.72 & 13.6 \\
\hline 60 & 2.86 & 9.4 \\
\hline 80 & 2.87 & 8.7 \\
\hline
\end{tabular}


It was observed from the above tables that porosity decreases as density increases in the both regions. As we known that, the main disadvantage of spray forming method is porosity. This problem can be minimized by the rolling process. Before rolling the percentage of total porosity in sample is $33.3 \%$ (in middle region), and after rolling it is $15.2 \%$.

Fig 5 shows the effect of percentage thickness deformation by rolling on the porosity of spray deposited $\mathrm{Al}-\mathrm{Si}-\mathrm{Pb}$ alloy. It can be seen the porosity decreases in both region ie. middle and peripheral after rolling. The decrease in porosity is due to metal flow in Thickness and length direction

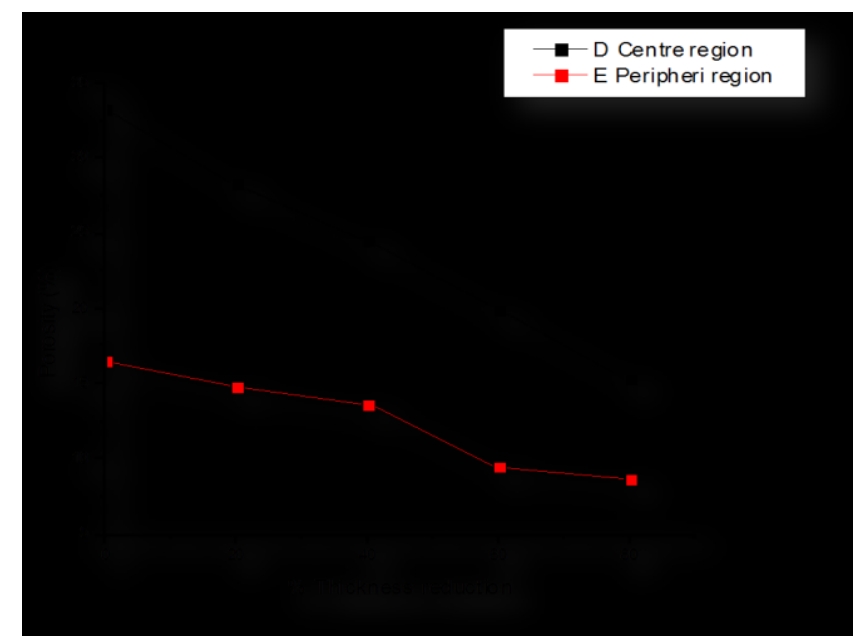

Fig 5.Porosity of spray deposited $\mathrm{Al}-6 \mathrm{Si}-20 \mathrm{~Pb}$ alloy as a function of percentage thickness reduction.

\subsection{WEAR RATE}

Wear rate as a function of applied load for different thickness reduction in $\mathrm{Al}-6 \% \mathrm{Si}-20 \% \mathrm{~Pb}$ alloy is shown in fig 6. Wear rate increases with the increase in applied load for all values of thickness reduction. Also, the wear rate is higher for without rolled sample.

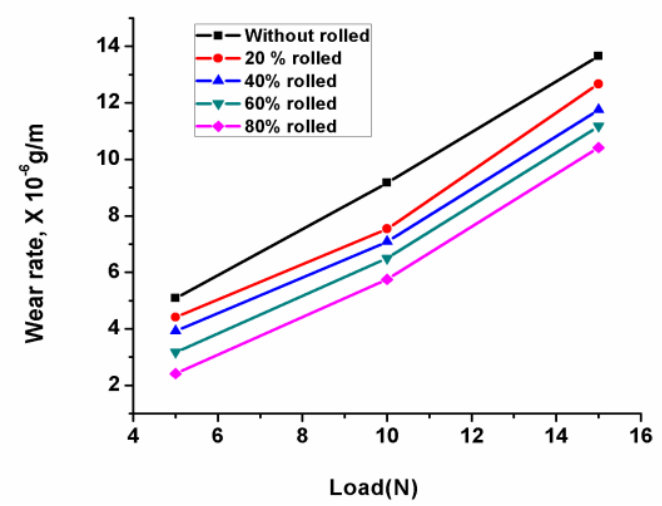

Fig 6.Variation in wear rate of $\mathrm{Al}-6 \mathrm{Si}-20 \mathrm{~Pb}$ alloy as a function of applied load for different thickness reduction Fig 7.Shows the variation in wear rate of spray deposit as a function of $\%$ reduction in thickness at different applied load. Wear rate decreases linearly with increasing the percentage reduction in thickness at all applied load. Obviously, the wear rate is higher at higher load. 


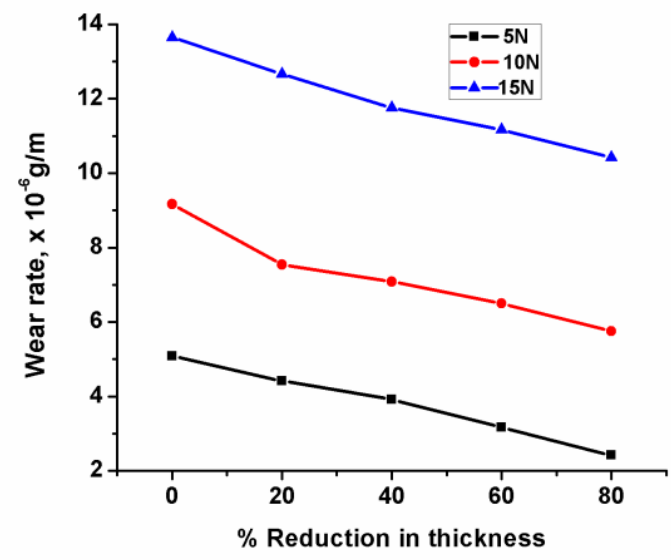

Fig 7. Variation in wear rate with different percentage thickness of Al-6Si-20Pb

\section{Conclusions}

The following conclusions are derived from the work of present investigation.

1.The porosity of spray formed deposit decreases from centre to periphery. No change in porosity in thickness direction.

2. With increment in the \% of rolling reduction of the sample porosity decreases in both regions ie .middle and peripheral region. The decrease in porosity is due to metal flow in thickness and length direction. 3.Increase in wear rate with the increase in applied load for all percentage of thickness reduction.

4. Wear rate decreases linearly with the increase in percentage of thickness reduction at all loads

\section{ACKNOWLEDGMENT}

I would like to extend my sincere gratitude to Dr. Devendra Singh, Asst. Prof. for suggesting an interesting study, for his able guidance, for the informative discussions and for his assistance which made this work possible and successful.

[1] P.S. Grant, Prog. Mater. Sci. 39 (1995) 497.

\section{References}

[2] R. Doherty, C. Cai, L. Kohler, Int. J. Powder Metall. 33 (1997) 50.

[3] An.j. Dong C. and Zhang Q.Y., "Improvement of the wear behavior of stircast Al-Si-Pb alloys by hot extrusion", Tribol.Int, 36 (2003) 25-34.

[4] Zhu M., Gao Y., Chung., Che Z.X., Luo K.C and Li B. D., "Improvement of wear behavior of Al-Pb alloys by mechanical alloying," Wear, 242, (2000) 47-53.

[5] An j.,Liu Y.B. and Lu Y, "Influence of $\mathrm{Pb}$ on the friction and wear behavior of Al-Si-Pb alloys, Mater. Sci. Eng. A 373, (2004 294-302”.

[6] Rudrakshi G.B, Srivastava V.C, Pathak J.P and Ojha S.N., "Spray forming of Al-Si-Pb alloys and their wear characteristics", Mater. Sci. Eng. A 383, (2004) 30-38.

[7] Mohan S., Agarwal V. and Ray S., "The effect of lead content on the wearcharacteristic of a stir-cast Al-Si-Pballoy", Wear, 140 (1990) 83-92.

[8] Fang X.,Fan Z., "Rheo-die casting of Al-Si- Zhao J.Z., Drees S. and Ratke L., "Strip casting of Al-Si-Pb alloys a numerical analysis", Mater. Sci. Eng., A282, (2000) 262-269.

[9] Yu F., Dwarakadasa D.S and Ranganathan S., Microstructure and mechanical properties of spray formed Al- Si- Pb alloys. J. Mater. Process. Technol., 137, (2003)164-167.

[10] Rudrakshi G.B., Srivastava V.C., and Ojha S.N., "Microstructural development in spray formed Al-3.5Cu-10Si-20Pb alloy and its comparative wear behavior in different enviormental conditions", Mater. Sci. Eng. A, 457, (2007)100-108.

[11] Pb immiscible alloys, Scripta Mater"., 54, (2006) 789-793.

[12] Suh Y.C. and Lee Z. H., "Nucleation of liquid $\mathrm{Pb}$ phase in hypermonotectic $\mathrm{Al}-\mathrm{Pb}$ melt andseggrigation of $\mathrm{Pb}$ droplets in melt spun ribbon', Scripta Metall. Mater., 33, (1995) 1231-1237. 